\title{
DISCUSSÃO SOBRE FORMAÇÃO DE PROFESSORES, INICIAL E CONTINUADA E A RELAÇÃO COM A NOVA BNCC
}

\author{
Discussion on teacher training, initial and continued and the relationship with the \\ new BNCC
}
Discusión sobre la formación docente, inicial y continua y la relación con el nuevo BNCC

\author{
Simone das Graças Leal * \\ Maria Célia Borges ** \\ Betânia de Oliveira Laterza Ribeiro***
}

\begin{abstract}
Resumo
O artigo traz uma discussão sobre a formação de professores e inclui aspectos históricos, teóricos ou conceituais e políticos relativos ao tema. Objetiva contribuir na discussão em alguns aspectos relativos às políticas e práticas de formação docente, os quais se encontram diluídos em aspectos da formação inicial, da formação continuada e da formação continuada em serviço atrelada à base curricular. $\mathrm{O}$ delineamento metodológico teve como base a pesquisa bibliográfica e documental. Destacamos a importância ínfima dada ao tema pelas políticas públicas, demarcadas nos parcos investimentos financeiros, nas descontinuidades dos projetos e na consolidação das práticas de formação ao longo da história. Nesse sentido, recentemente, a Resolução $\mathrm{n}^{\circ} 2$ de 2015, que representava um avanço para a Diretrizes Curriculares, foi substituída pela Resolução $\mathrm{n}^{\circ} 2$ de 2019 , indicando um perfil mais tecnicista para o profissional docente. Ressaltamos a urgência da luta coletiva por mudanças na valorização da empreitada da formação de professores, o que vai, certamente, incidir na melhoria da qualidade de ensino nas escolas públicas.
\end{abstract}

PALAVRAS-CHAVE: Políticas e práticas de formação de professores. Formação inicial e continuada. Diretrizes e Base Curriculares Nacionais.

\footnotetext{
Abstract

* Mestre em Educação pela Universidade Federal do Triângulo Mineiro (UFTM). Pedagoga na EE. Aurélio Luiz da Costa. E-mail: simonegracasleal@gmail.com. Orcid. https://orcid.org/0000-0001-97461361

** Doutora em Educação pela PUCSP. Docente na graduação e pós-graduação da Educação na Faced/UFU. E-mail: mariacelia@ufu.br. Orcid: http://orcid.org/0000-0002-5445-023X

*** Doutora em Educação pela USP. Docente na graduação e pós-graduação da Educação na Universidade Federal de Uberlândia (UFU). E-mail: laterzaribeiro@uol.com.br. Orcid: https://orcid.org/0000-0002$3708-4506$
} 
This article discusses the teacher training and includes historical, theoretical or conceptual and political aspects on the theme. It aims to contribute to the discussion related to some of the aspects concerning teacher training policies and practices, which are diluted into aspects of initial training, continuous training and continuous training in service linked to the National Curricular Guidelines and Basis. The methodological design was based on bibliographic and documentary research. We highlight the very small importance given to the theme by public policies, limited by the scarce financial investments, the discontinuities of the projects and the consolidation of training practices throughout history. In this sense, recently, Resolution $\mathrm{n}^{\circ}$ $2 / 2015$, which represented an advance for the Curricular Guidelines, was replaced by Resolution $\mathrm{n}^{\mathrm{o}} 2 / 2019$, indicating a more technical profile for the teaching professional. We emphasize the urgency of a collective struggle for changes to value teacher training, which will certainly affect the quality of teaching in public schools.

KEYWORDS: Teacher training policies and practices. Initial and continuous teacher training. National Curricular Guidelines and Basis.

\section{Resumen}

El artículo discute sobre la formación de los profesores e incluye aspectos históricos, teóricos o conceptuales y políticos relativos al tema. Tiene como objetivo contribuir a la discusión de algunos aspectos relacionados a las políticas y prácticas de formación docente en los cuales se encuentran diluidos aspectos de formación inicial, de formación continuada y de formación continuada en servicio asociado a los Lineamientos y Bases Curriculares Nacionales. El diseño metodológico estuvo fundamentado en la investigación bibliográfica y documental. Destacamos la poca importancia que se le da al tema de las políticas públicas, demarcadas en escazas inversiones financieras, en las discontinuidades de los proyectos y en la consolidación de las prácticas de formación a lo largo de la historia. En este sentido, recientemente, la resolución $n^{\circ}$ 2 de 2015, que representaba un avance en los Lineamientos Curriculares, fueron sustituidas por la resolución $\mathrm{n}^{\circ} 2$ de 2019, indicando un perfil más técnico para la profesión docente. Resaltamos la urgencia de emprender la lucha colectiva en lograr cambios en la valoración de la formación de profesores, que sin duda influenciará en la mejoría de la calidad de la enseñanza en las escuelas públicas.

PALABRAS CLAVE: Políticas y prácticas de formación de profesores. Formación inicial y continuada. Lineamientos y Bases Curriculares Nacionales.

\section{INTRODUÇÃO}

A formação de professores é objeto de estudos nas pesquisas atuais e muito pertinente no momento político em que vivemos, pois assistimos várias mudanças nas políticas sociais e educacionais e que, comumente, não representam avanços, mas, pelo contrário, retrocessos demarcados por perdas de conquistas outrora alcançadas.

O objetivo deste $\operatorname{artigo~}^{1}$ é contribuir na discussão em alguns aspectos relativos à formação de professores que se encontram fragmentados em formação inicial, formação continuada e formação continuada em serviço, além de estarem articulados à nova Base

\footnotetext{
${ }^{1}$ Este artigo é um recorte do estudo apresentado na dissertação de Mestrado defendida em 2018, na Universidade Federal do Triângulo Mineiro, da qual uma seção foi reestruturada para a presente apresentação.
} 
Nacional Comum Curricular (BNCC). Como metodologia optamos pelo delineamento da pesquisa bibliográfica para a construção do referencial teórico e da pesquisa documental, com análise de documentos pertinentes à discussão.

\section{O debate sobre a Formação Inicial e Continuada de Professores}

Desde o Brasil colônia temos enfrentado o descaso com a educação pública, visto que esta era privilégio da elite econômica, sendo que o tempo, e mudanças nas legislações, não foram suficientes para suprir as lacunas deixadas pela história. Nessa perspectiva, Gatti (2013-2014) ressalta a morosidade da escolarização em nosso país e a indispensabilidade da inclusão das crianças e jovens menos abastados financeiramente, que ficaram à margem da sociedade, nas redes de ensino, visto que até bem pouco tempo não eram atendidos pela Educação Básica.

Assim, a formação de professores é uma das implicações decorrentes do desafio imposto pela expansão das redes de ensino em tempo reduzido, ocasionando uma busca de quantidade em detrimento da qualidade, na formação de professores, para atender à demanda e carência da população brasileira. Borges, Aquino e Puentes (2011, p.94) esclarecem que em nível global a preconização da formação de professores foi feita por Comenius no século XVII; porém, apenas no final do século XVIII, após a Revolução Francesa, é que foram criadas as primeiras escolas normais cujo objetivo era formar professores, germinando a sistematização da organização educacional.

No Brasil colônia os jesuítas foram os responsáveis pela educação em uma aliança com os colonizadores, com o objetivo principal de catequizar e fazer com que os nativos acatassem as condições impostas pelos portugueses. No parecer de Seco e Amaral (2006), após longos anos à frente da instrução no Brasil e serem responsáveis pela fundação de vários colégios da congregação, foram expulsos do país e introduzidas as reformas pombalinas, que implantaram as aulas régias ou avulsas de Latim, Grego, Filosofia e Retórica, visando substituir o modelo educacional organizado pelos jesuítas que, embora não fosse o ideal, era o único sistema existente. As reformas pombalinas não tinham como objetivo a formação dos professores ou a educação popular, mas tão somente atender às demandas das circunstâncias históricas, ou seja, preparar pessoas capazes de assumir postos de comando no estado, concentrando toda a educação nas mãos do estado. No início do século XIX, conforme os autores, Dom João VI criou cursos superiores no Brasil. Todavia, a preocupação com a formação de professores só surgiu em outubro de 1827, quando foi promulgada a Lei das Escolas das Primeiras Letras.

Com os debates sobre a necessidade de expansão, organização curricular na primeira década do século XX, foi criada a Associação Brasileira de Educação. Em 1932 foram tomadas iniciativas visando abranger aspectos culturais amplos e profissionais, culminando com a "organização dos Institutos de Educação", que trouxe o ideário da Escola Nova. Gadotti (1998) reporta que os teóricos da escola nova consolidaram sua posição antiautoritária, opondo-se à escola centrada na autoridade dor professor, contribuindo para a difusão das teorias dialógicas, desenvolvimento da escola pública, Psicologia e Sociologia.

No decurso da história foram criados os cursos de Pedagogia que formavam professores para lecionar nas escolas Normais e de Licenciatura, que formavam 
professores para lecionar as diversas disciplinas das escolas de quinto ao oitavo anos, bem como em escolas secundárias. A partir do Decreto $\mathrm{n}^{\circ}$ 1.190, de 04 de abril de 1949, foi introduzido o modelo $3+1$, em que durante três anos estudavam as disciplinas específicas equivalentes ao bacharelado e, no último ano, a formação didática, para se obter a Licenciatura.

Gonçalves e Borges (2017) constatam que o curso de Pedagogia, cujo currículo oferecia minguada formação para professores, tinha como objetivo formar técnicos para trabalhar na educação e, com apenas mais um ano do Curso de Didática, estaria apto a trabalhar como docente em escolas normais e na educação primária. Verificamos que desde os primórdios da história da formação de professores no Brasil, fica explícita a formação de um sistema híbrido.

Por conseguinte, sob o domínio do regime militar, por meio da Lei $\mathrm{n}^{\circ} 5.540$, de 28 de novembro de 1968, o Congresso Nacional aprova a Reforma universitária, deixando clara a opressão e supremacia do estado, resultando em uma série de mudanças na educação, principalmente no ensino superior. Houve, portanto, a ratificação que desde a década de sessenta a preocupação dos cursos de formação inicial era atender às necessidades do mercado capitalista e reforçar a autocracia do estado, mantendo todos os domínios da educação em suas mãos.

Nos anos setenta, por força da Lei $n^{\circ} 5.692 / 1971$, a educação brasileira é reformulada, extinguindo a escola Normal, introduzindo o magistério agregado ao atual ensino médio. Essa lei foi alterada em 1982 e criada a licenciatura "curta" com o intuito de formar professores com uma menor carga horária para lecionar do quinto ao oitavo ano do Ensino Fundamental, conforme a circunstância econômica e social que a época exigia.

Gatti e Barreto (2009) pontuam que a LDB no 9394/1996 estipulou exigências de nível superior para os professores de Educação Básica, mas, ainda permitindo a formação no ensino médio para a Educação Infantil, o que representou um retrocesso. Alterações foram propostas para os cursos de formação de professores, após um período relativamente grande de transição. Apenas após 2002 foram iniciadas as adaptações curriculares, por intermédio das diretrizes curriculares, e aprovadas pelo Conselho Nacional de Educação (CNE). As universidades tiveram a autonomia de organizar cursos de formação de professores, baseados em seus projetos institucionais, com a exigência de que as licenciaturas fossem plenas.

Ademais, segundo a visão de Gatti e Barreto (2009), esse norteamento levou a uma formação fragmentada e sem uma fiscalização eficaz, corroborando para a baixa qualidade nas formações dos docentes. A urgência em cumprir a legislação, e inserir o país no mercado mundial, exigiu que todos os professores da Educação Básica, do primeiro ano do ensino fundamental ao terceiro ano do ensino médio, tivessem formação com licenciatura plena. As instituições públicas e particulares oportunizaram cursos para atender o mercado e, mais uma vez, a humanização da educação foi deixada de lado, em detrimento ao atendimento das demandas do campo político e econômico.

Gonçalves e Borges (2017) destacam três eventos internacionais criados com o objetivo de alicerçar a educação brasileira e de demais países em desenvolvimento. $\mathrm{O}$ primeiro foi a "Conferência Mundial de educação para Todos" (Jomtien, Tailândia, 1990), onde foram acordadas ações que deveriam ser cumpridas e, dentre elas, merece 
destaque a formação de professores para o alcance das metas, destacando o aporte financeiro do Programa das Nações Unidas para o Desenvolvimento (PNUD), o Banco Mundial (BM) e a United Nation Educational Scientific Cultural Organization (UNESCO), bem como o Fundo das Nações Unidas para a infância (UNICEF). O segundo evento foi a elaboração, e implementação, de dois documentos feitos pela Comissão Econômica para a América Latina e Caribe (CEPAL), sendo eles precursores do lema "Transformação produtiva com Equidade", cuja perspectiva seria que a educação deveria proporcionar conhecimentos e competência úteis ao sistema produtivo. O segundo evento foi "Educação e conhecimento: eixo de transformação produtiva com equidade", com a meta de capacitar, e incorporar o progresso científico e a tecnologia para possibilitar a mudança das estruturas produtivas para uma delimitação de igualdade social.

Numa visão crítica notamos que todas essas concepções internacionais pregam uma educação de qualidade tendo, porém, como prioridade, a formação do sujeito para atender o mercado de trabalho e não a formação do ser humano, filiados ao paradigma neoliberal. Nesse prisma, a formação de professores na contemporaneidade apresenta uma herança histórica, política, social e econômica com resquícios de desigualdade social, autoritarismo do estado e um currículo fragmentado que não atende às necessidades da educação atual.

Diante do exposto, é notório que o cenário brasileiro explicita uma deficiência na formação de professores que afeta diretamente a formação integral dos estudantes, a atuação do professor em sala de aula, e a ampliação acelerada das redes de ensino, acarretando uma demanda maior de profissionais docentes. Teve como consequência uma formação aligeirada com uma qualificação inadequada.

Aqui buscamos levar nossos pares à reflexão e alertar as políticas públicas quanto à necessidade emergente de alavancar e investir na formação profissional docente, e não apenas importar modelos externos que não condizem com o contexto educacional brasileiro, introduzindo-os de forma abrupta e tempestiva no seio do nosso povo, cujo dever do estado é oferecê-la, conforme Capítulo III, seção I, artigos 205 e 206 parágrafos I ao VII da Constituição Brasileira (1988).

A palavra formação nos remete a uma definição polissêmica, pois, acomete vários significados e conceitos dentro do processo ensino aprendizagem. Na concepção de Nóvoa (1991), a formação abarca o desenvolvimento pessoal, profissional e organizacional e, por isso, essas três dimensões devem ser contempladas e articuladas dentro das instituições educacionais e no contexto da formação de professores. Assim, o termo formação, dependendo do contexto social, regional e sua concepção teórica, pode ser entendido como: capacitação, qualificação, aperfeiçoamento, reciclagem, atualização, formação continuada, formação permanente, aprofundamento, treinamento, aprimoramento, desenvolvimento profissional, compensação, profissionalização. "A "formação em serviço" entende a pessoa como um ser humano integral, com múltiplos valores, conhecimento, atitudes, aptidões e hábitos." (ALVARADO PRADA, 1997, p.89).

Reportando-nos ao caráter antagônico do termo formação que abarca uma multiplicidade de atribuições, engendramos levantar a concepção de formação inicial, continuada e continuada em serviço, na perspectiva de autores como Veiga (2009) que retrata a formação inicial como a preparação articulada às ações que visam formar o 
docente para o exercício profissional. Paula (2009) refere-se à formação inicial como uma tessitura pré-serviço, no sentido de que esta vem antes do ingresso do docente no campo de atuação do exercício profissional do magistério.

O enfoque de Chimentão (2009) é de que a formação continuada resulta da necessidade de transformação do professor, visto que é por meio do constante aprimoramento que é possível o desenvolvimento, o progresso. O autor argumenta que a formação continuada só será significativa se ocorrer de forma a dotar o profissional docente de conhecimentos consistentes com características e aptidões segmentadas não apenas em sala de aula, mas, em todo o contexto educacional. Candau (1997) ratifica que a formação continuada não deve ser vista como um acúmulo de cursos, palestras, etc., mas, sim, por intermédio da crítica reflexiva e permanente. Nesse sentido, a formação continuada deveria qualificar os professores de forma permanente diante das deficiências identificadas em sua prática; no entanto, tem se observado que na realidade não é isso que vem ocorrendo, pois, esta tem sido interpretada e implantada como um preenchimento das lacunas deixadas pela formação inicial.

Ao se referir à concepção de formação continuada em serviço Alvarado Prada (1997, p. 115) evidencia que a formação realizada no local de trabalho do docente, juntamente com outros atores da escola, permite uma interlocução contínua de suas vivências e crescimento das relações. Destaca a oportunização e autoconhecimento do cotidiano e que "(...) a rotina tem mecanismos de auto-proteção nos quais algumas relações são ocultas e não se evidenciam como tais." (ALVARADO PRADA, 1997, p.114). Tal autor enfoca que a formação realizada no local de trabalho do docente, juntamente com outros atores da escola, permite uma interlocução contínua de suas vivências e crescimento das relações.

A formação continuada em serviço apresenta um significado abrangente e diverso, dependendo do contexto em que está inserida. Temos como exemplo a formação continuada para que o docente em exercício, ou atuação dentro da escola, alcance a titulação exigida para sua função, como a Proformação ${ }^{2}$ implementada pelo MEC (GATTI, 2008). Ademais, formação continuada em serviço pode ser entendida por concepções diferentes dependendo da região, das instituições e de vários outros fatores que influenciam o processo. Alvarado Prada (1997), refere-se à "formação em serviço" como sendo atividade em prol do desenvolvimento integral do educador, com sua essência, valores, habilidades, informações, saberes, crenças e que esta precisa fomentar todas essas dimensões para exercer seu papel com eficácia e propriedade. $\mathrm{O}$ autor reporta a necessidade de que as formações continuadas em serviço oportunizem aos docentes a concepção de novas conexões, visões de mundo, possibilitando-lhes a escolha de novas perspectivas no fazer pedagógico. Dessa forma, uma das alternativas seria a atuação do professor como pesquisador dentro do espaço de trabalho, transformando situações rotineiras do contexto diário do trabalho com a participação coletiva dos atores da escola (ALVARADO PRADA, 1997, p.147).

Pressupomos que ao falarmos em formação continuada em serviço, e formação continuada, pode parecer que estamos nos reportando ao mesmo tema. No entanto, a primeira refere-se a um intercurso da formação inicial, embasada nas políticas públicas

\footnotetext{
${ }^{2}$ Programa da Secretaria da Educação a Distância, é um curso em nível médio, com habilitação para o magistério na modalidade normal, realizado pelo MEC em parceria com estados e municípios. Iniciou sua oferta em 1999, nas regiões norte, nordeste e centro-oeste.
} 
de reforma da educação. Quanto à formação continuada em serviço, esta se refere à expressividade do fazer do professor, centrada no lócus onde ocorre o processo ensino aprendizagem, sendo o professor o produtor do conhecimento, por intermédio das informações obtidas no decurso de sua prática. $\mathrm{O}$ autor ratifica a importância de ambas na formação de professores e reitera que embora sejam distintas, elas se complementam, cada uma com sua especificidade.

Há autores como Santos (2011, p.4) que refutam as políticas de formação continuada, que tem a escola como espaço privilegiado de formação, visto que o docente, tendo um salário reduzido, se vê na obrigatoriedade de ter dupla jornada de trabalho em sala de aula, muitas vezes em duas ou mais escolas. Esses fatores dificultam a perspectiva de construção coletiva no domínio escolar.

Ademais, as definições, e conceitos de formação docente, nos instigam a trilhar por caminhos pouco explorados, ou seja, a formação continuada de professores no cotidiano da instituição onde atuam, considerando que poucos autores enveredaram pela investigação da formação continuada em serviço, que acontece no lócus da instituição escolar. Nóvoa (1991), desde a última década do século XX, acredita nessa perspectiva, salientando que não basta que a formação seja feita na instituição. Faz-se necessário que sua abordagem atenda às reais necessidades dos docentes que nela atuam. Nesse prisma, o autor ratifica que as formações no local de trabalho só se justificam se os projetos de formação tiverem como vertente as ações pedagógicas diante de problemas específicos da instituição educacional e dos profissionais docentes em relação ao seu fazer pedagógico e não em torno de conteúdos acadêmicos.

Conjecturamos, mediante vários estudos, que a formação ou capacitação do professor seja a solução para uma Educação Básica de qualidade e que faça um cruzamento de fronteiras entre os diferentes sujeitos que estão inseridos dentro da escola, entrelaçando os saberes científicos com os saberes do cotidiano, formando indivíduos capazes de fazer uma leitura crítica de mundo para além do letramento. Que as escolas de Educação Básica deixem de ser reprodutoras, ratificadoras do conteudismo, possam ser um espaço de encontros e desencontros entre subculturas e que o estudante possa ser sujeito da própria história. Destaca-se, ainda, a identidade do professor, suas crenças, valores, como um dos fatores inseparáveis do desenvolvimento profissional.

Nesse sentido, a formação continuada segue sendo efetivada em cursos e palestras desvinculados da realidade escolar. As formações continuadas em serviço estão aquém da perspectiva contemporânea, centrando principalmente nos profissionais que atuam sem a formação exigida pela legislação e não no sentido de formação continuada em serviço dentro da instituição educacional, o que "[...] implicaria em um conhecimento destes sobre as relações cotidianas que acontecem na instituição onde trabalham", conforme Alvarado Prada (1997, p. 116). O estado continua centralizando a formação, o currículo e o fazer pedagógico, empregando as mesmas ferramentas de uma sociedade historicamente burguesa, em dissonância com as exigências do século XXI.

A temática formação continuada é bastante abrangente, sinalizando para atribuições diversas que, dependendo do entendimento, as argumentações acerca do conceito podem ter e, segundo Gatti (2008, p. 58), o advento de tantas formações não ocorreu ocasionalmente e estas foram historicamente construídas. Gatti (2008) ressalta que a maior relevância talvez não seja o conceito, mas, sim, as limitações dos cursos 
oferecidos após a graduação, ou ingresso na carreira docente, pois, o conceito tem se mostrado, de forma ampla e indefinida, podendo ser entendido como atividades diversas que venham contribuir com a prática docente, horas de reunião coletiva no local de trabalho, reuniões pedagógicas, troca de experiências, cursos avulsos, extensão, cursos de diversos formatos oferecidos pela Secretaria de Educação e/ou seus parceiros, incluindo sistemas virtuais de aprendizagem. Conforme a autora, qualquer sensibilização profissional que leve à informação, reflexão e discussão, dentro ou fora do trabalho, é rotulada como formação continuada. Dessa forma, torna-se complexo o número de situações colocadas sob o rótulo de formação continuada, sendo oferecidos pelos mais diversos setores, não demarcando apenas a educação. Gatti (2008, p. 58) afirma que o advento de tantas formações não ocorreu ocasionalmente e que estas foram historicamente construídas. A autora avalia a formação continuada da forma em que está posta, como sendo uma resposta das políticas públicas aos problemas e dilemas enfrentados em nosso sistema educacional. A ideia de uma formação permanente minimiza o senso comum da fragilidade da educação brasileira.

Nos últimos anos cresceu o leque de ações voltadas à formação continuada, sinalizando ora para estudos estruturados oferecidos após a graduação, ora como complemento da formação inicial, por meio de cursos avulsos, ou de extensão, para o professor em atividade funcional e, ainda muitas vezes, como cursos genéricos que contribuem de alguma forma para a prática do professor em sala de aula. Destacam-se, também, os cursos online oferecidos a distância, seja por Secretarias da Educação, seja por instituições particulares.

Nóvoa (1995) relaciona a formação docente em três dimensões, sendo a primeira delas a pessoal, por estar imbricada com sua história de vida; a profissional, por estar alinhada à sua experiência como educador; e a organizacional, pois, a escola é um lócus educativo. Assim, são muitos fatores que intervêm na formação do profissional docente e todos eles influenciam e têm a sua importância.

Por conseguinte, Paula (2009) afirma que a formação continuada é uma formação permanente proporcionada e planejada por instituições, ou pelo próprio docente durante sua vida profissional, visando sanar dificuldades, melhorar a prática e habilidades profissionais. Gonçalves e Borges (2017) apontam que na LDBEN 1996, no artigo 62, inciso III do art. 61, e no art. 63 inciso II, são indicados novos rumos para a formação de professores, sendo que este último inciso refere-se à oportunidade de formação para quem dispõe de diploma superior e queira se dedicar ao magistério de Educação Básica e à obrigatoriedade da formação continuada. O inciso III aborda a obrigatoriedade de manutenção de formação continuada para todos os profissionais da educação. Em nossa visão, o inciso II vem desqualificar a profissão docente, pois, qualquer profissional pode fazer um complemento pedagógico (de certa forma uma formação continuada) e equiparar-se a um profissional que optou pelo magistério e fez sua formação inicial dentro do currículo do ser docente. Diante da prerrogativa da Lei, cada estado e cada município geram maneiras de cumprir a LDBEN oferecendo cursos, palestras, congressos e formação continuada em serviço; no entanto, na maioria das vezes, estas formas de contemplar a LDBEN se dá de forma desarticulada com a necessidade docente.

Gatti (2008) discorre que nos últimos anos do século $\mathrm{XX}$ as divisões profissionais e universitárias dos países desenvolvidos têm sido palco de amplas 
discussões sobre a importância da formação de professores para o novo século e as inovações advindas da globalização ${ }^{3}$, das tecnologias da informação e comunicação, do novo contexto social, do mercado econômico, financeiro e, concomitantemente, das novas exigências do mercado de trabalho. A autora afirma que a formação continuada em nosso país tenta suprir falhas, e/ou espaços deixados pela formação inicial, mas, que assemelham-se a programas compensatórios e não propriamente um aprofundamento e desenvolvimento na formação, principalmente no setor público em contraponto ao que vem sendo discutido internacionalmente.

Na década de noventa Gatti (2008) destaca dois programas de capacitação que tiveram relevância no cenário nacional, financiados pelo Banco Mundial. O primeiro deles é o Programa de Capacitação de Professores (PROCAP), desenvolvido no estado de Minas Gerais objetivando capacitar professores para atuar nos primeiros anos do Ensino Fundamental, modalidade à distância, com agendamento dentro do calendário escolar e incentivo para os professores participantes. O segundo é o Programa de Educação Continuada (PEC), implementado pelo estado de São Paulo buscando abranger os profissionais do Ensino Fundamental (professores, diretores, técnicos), em sistema presencial. A autora destaca alguns programas implementados pelo Ministério de Educação e Cultura (MEC) com a denominação de formação continuada como o Programa de Formação de Professores em Exercício (PROFORMAÇÃO), com o intuito de complementar a formação dos professores em exercício, provendo a titulação adequada a seu cargo. Além do setor público, muitas instituições privadas investiram nos cursos de formação continuada de professores, principalmente na modalidade à distância. A preocupação com a formação de professores entrou na pauta mundial, afiançada por documentos internacionais, fazendo com que políticas públicas e atitudes políticas realizem mudanças curriculares e alterações nas formações docentes.

Questionamos quais seriam os reais interesses das organizações internacionais ao interferir e financiar formações continuadas em nosso país. Denota-se que a intenção é fomentar o material humano para atender à demanda do mercado de trabalho, preparando professores e estudantes para o século XXI. Porém, fica a interrogação se essa seria a solução para os novos tempos, visto que a humanização da educação não está sendo refletida nas formações. A legislação brasileira no que se refere à formação continuada tem um longo caminho a percorrer porque conquistas obtidas até o momento retratam processos de embate, com movimentos e negociações ocorridos ao longo da nossa história.

Desse modo destacamos que a Associação Nacional pela Formação dos Professores em Educação (Anfope, 2000), ao fazer analogia entre a formação continuada e a formação profissional, afirma que a formação continuada deve sinalizar como resultado de uma extensa amarração entre espaços heterogêneos que incluem formação inicial, continuada e continuada em serviço, em aspectos políticos, sociais e culturais dentro e fora da escola.

É certo que formação inicial, continuada e continuada em serviço são fases da construção profissional docente. Prática e teoria precisam caminhar juntas, estão em

\footnotetext{
${ }^{3}$ A globalização é, de certa forma, o ápice do processo de internacionalização do mundo capitalista. Para entendê-la, como, de resto, a qualquer fase da história, há dois elementos fundamentais a levar em conta: o estado das técnicas e o estado da política. SANTOS, Milton. Por uma outra globalização - Do Pensamento único à consciência universal, Rio de Janeiro-São Paulo: Editora Record, 2001.
} 
constante processo e se fazem necessárias, pois, ambas devem estar relacionadas para que ocorra a hominização da educação e atendam à demanda da contemporaneidade. Corroborando com a discussão, Imbernón (2010) afirma que a formação continuada ultrapassa uma atualização de conhecimentos científicos, pedagógicos, pois, no contexto atual é necessária uma formação que oportunize a adaptação para conviver com incertezas, transformações e tomadas de decisões intrínsecas ao ambiente educacional.

Ferreira (1996) deixa explícito que o profissional docente não tem espaço para desenvolver sua autonomia, visto que as ações são encaminhadas e direcionadas por preceitos coletivos e impostos por prerrogativas institucionais que objetivam "adequar" o docente ao sistema. $\mathrm{O}$ conhecimento e a formação são uma continuidade que evoluem de forma constante. Portanto, não devem ser tolhidos por normas e regras e, sim, permitir a preparação de docentes atualizados e inovadores. Resende e Isobe (2017, p. 287) trazem sua contribuição, ressaltando que "No Brasil, a predominância de determinados modelos de gestão em educação... engendrou uma forma de organização do ensino fundamentada na competição e na busca de eficiência, transformando a educação em mercadoria".

Neste momento histórico destacamos que na Resolução CNE/CP no 2/2015, elaborada pela Comissão Bicameral de Formação Inicial e Continuada de Professores do Conselho Nacional de Educação, as orientações fortaleciam uma concepção de formação indissociável de uma política de valorização profissional dos professores para formação, carreira e condições de trabalho e representa um consenso educacional sobre uma concepção formativa da docência que articula indissociavelmente a teoria e a prática, dentro de uma visão sócio-histórica, emancipadora e inclusiva, defendida pelas entidades acadêmicas do campo da educação.

Embora ela tenha sido aprovada em 2015, começou a ser discutida em 2004, e apresentava "(...) um elemento novo em relação à anterior, pois, juntamente com a formação inicial procura-se enfatizar também a formação continuada dos professores, considerada elemento fundamental para o bom exercício profissional" (VOLSI, 2016, p.1505). Esse é um dos aspectos que lhe garantem ser uma proposta que coincide com os anseios dos profissionais da educação e, por isso, é válido destacar a “(...) percepção de que ali estão sintetizados os fundamentos da educação brasileira construídos ao longo de pelo menos três décadas pelos educadores progressistas" (BAZZO; SCHEIBE, 2019, p.673).

No entanto, por apresentar esses fundamentos acima descritos, as DCNs encontraram resistência por parte das instituições privadas preocupadas com o aumento dos custos com as licenciaturas e, sobretudo, na "rede federal, a ampliação de carga horária deveria ter sido acompanhada de aumento no número de vagas de docentes nas universidades. Porém isso não se concretizou, o que acabou criando entraves para a implementação (...)" (ANADON; GONÇALVES, 2018, p.45). E, ainda,

[...] a materialização ou não das mesmas e vai requerer políticas nacionais que priorizem a formação e as condições de profissionalização destes profissionais por meio de equiparação salarial, discussão e aprovação de diretrizes sobre carreira, cumprimento do piso salarial nacional, melhoria das condições de trabalho, entre outros elementos que devem ser tratados organicamente e à luz da agenda instituinte do Sistema Nacional de Educação (DOURADO, 2016, p.36). 
Vale destacar que essa diretriz foi revogada antes de sua implantação, uma vez que as orientações e políticas educacionais são sempre instáveis e mudam a cada governo, não tendo tempo de se efetivarem ou concretizarem seus objetivos.

A Resolução no 2 de 2019 "Define as Diretrizes Curriculares Nacionais para a Formação Inicial de Professores para a Educação Básica e institui a Base Nacional Comum para a Formação Inicial de Professores da Educação Básica (BNC-Formação)”. Aconteceram vários manifestos contrários a essa nova resolução, os quais denunciavam que tais orientações não consideravam as políticas instituídas anteriormente; ignoravam a produção e o pensamento educacional brasileiro - as pesquisas e avanços na área educacional; retomavam concepções ultrapassadas como a Pedagogia das competências e a concepção tecnicista da Didática; apresentavam uma visão restrita e instrumental de docência e negativa dos professores; descaracterizavam os núcleos formativos, a formação pedagógica e a segunda licenciatura; ignoravam a diversidade nacional, a autonomia pedagógica das instituições formadoras e sua relação com a Educação Básica; e relativizavam a importância dos estágios supervisionados retrocedendo, desse modo, nos avanços que a área alcançou com a Resolução 02/2015. Os manifestos não foram ouvidos.

Quanto à formação de professores, tal proposta orienta para a institucionalização de Institutos Superiores de Educação, assim como a proposição de referenciais docentes de caráter meritocrático para a valorização do professor (formação, carreira, salário e condições de trabalho), entre tantas outras impropriedades. Importante é formar o professor com informações para o "saber fazer" com as "aprendizagens essenciais" para a constituição do indivíduo trabalhador, e consumidor, o que é essencial para a sociedade capitalista.

Nesse prisma, para confirmar a visão tecnicista e pragmática da resolução em pauta, é importante ressaltar o que traz a Resolução $n^{o}$ 2, 2019 no Art 12, ítem II, letra c) manejo dos ritmos, espaços e tempos para dinamizar o trabalho de sala de aula e motivar os estudantes. Este item nos mobiliza a pensar e refletir sobre a história da Didática, especialmente na sua perspectiva tecnicista, seus avanços e retrocessos.

Segundo Dourado (2016) a materialização, ou não, das DCNs exige políticas nacionais que considerem a formação e as condições de profissionalização, por intermédio de equiparação salarial, das diretrizes sobre carreira, atendimento do piso salarial nacional, melhoria das condições de trabalho, dentre outros aspectos que devem ser tratados seriamente num Sistema Nacional de Educação bem instituído, e não por meio de orientações e políticas educacionais sempre instáveis e que mudam a cada governo, sem tempo de efetivação ou concretização de seus objetivos.

Nas DCNs de 2019, a formação continuada aparece apenas no "CAPÍTULO II DOS FUNDAMENTOS E DA POLÍTICA DA FORMAÇÃO DOCENTE”.

VII - a articulação entre a formação inicial e a formação continuada; VIII - a
formação continuada que deve ser entendida como componente essencial
para a profissionalização docente, devendo integrar-se ao cotidiano da
instituição educativa e considerar os diferentes saberes e a experiência
docente, bem como o projeto pedagógico da instituição de Educação Básica
na qual atua o docente (BRASIL, 2019, p.3)

Nesta citação percebemos o impacto da nova BNC-Formação sobre a formação continuada, representando um grande retrocesso, uma vez que elimina as diretrizes 
relativas à formação continuada e à valorização dos profissionais do magistério, em resposta em um documento divulgado no dia 4 de novembro de 2019, destacando que " (...) a formação continuada de professores da Educação Básica (por) apresentar uma maior complexidade em termos da diversidade da oferta, suas diretrizes de formação serão objeto de legislação própria (Parecer e Resolução) por parte deste CNE (FREITAS, 2020, p.1).

$\mathrm{Na}$ visão de Freitas (2018) o CNE deixa claro que está em sintonia com proposições de caráter tecnicista e praticista, “(...) retirando das Universidades a possibilidade de formação solidamente constituída no campo das ciências da educação e das ciências pedagógicas" (FREITAS, 2018, p.2). Nesse sentido, as mudanças representam retrocesso e não avanço.

Nas novas orientações percebemos que a ação visa alinhar a formação inicial e continuada de professores à BNCC, objetivando a implementação eficaz da base, pois, acreditam que os professores serão agentes ativos na implantação dela. Isso já reafirma que a BNCC é um retrocesso na educação brasileira e que trabalha na perspectiva de formação por competências.

A BNCC prioriza a formação de curta duração e prioriza ensinar os professores a saber fazer, buscando "os treinamentos dirigidos por especialistas, baseados na epistemologia da prática, distanciando os professores do desenvolvimento profissional ou da aprendizagem/crescimento emancipador" (MAGALHÃES, 2019, p.199). Entretanto, acreditamos que não se deve fazer dos professores "seguidores de instrução" e conduzi-los a determinada prática, uma vez que estes, que estão na prática no cotidiano da sala de aula, devem ter a liberdade de agir como sujeitos do processo didático-pedagógico, por serem os que conhecem suas reais necessidades e devem, portanto, ter autonomia para decidir sobre elas.

O contexto neoconservador, em que se encontra nosso país, reitera que a BNCC é mais uma forma de controlar os professores que serão avaliados pelo sucesso, ou fracasso, dos seus alunos e ainda terão sua formação realizada a partir de receitas que invadem as universidades, o que já pode ser percebido em programas como o novo Pibid e a Residência Pedagógica.

Conjecturamos, desse modo, o motivo da BNCC representar não um ganho, mas, sim, um retrocesso na educação. Têm ocorrido ameaças aos projetos educacionais democráticos e a forma como a BNCC vem sendo implementada e o discurso da mídia, por meio de propagandas governamentais, têm sido mecanismos de persuasão sobre as pessoas com a argumentação de que ela é um processo de participação social e que defende uma suposta igualdade de oportunidades educacionais (CÁSSIO, 2018).

Diante dessa persuasão, entendemos que a discussão sobre os objetivos e o papel da BNCC deve fazer parte dos cursos de formação inicial e continuada de professores. Não se pode esquecer que

[...] a BNCC é parte de uma política mais ampla que vem sendo implementada a partir do impeachment de Dilma Rousseff. Nesse contexto, é preciso, de modo coletivo e propositivo, retomar e continuar lutando por uma agenda democrática e inclusiva no campo da educação, visando a enfrentar a perda de direitos e a ideologia conservadora da política e das ações em curso; as diferentes formas de terceirização e privatização; o gerencialismo e a lógica do privado, que concebe a educação como mercadoria e naturaliza a dinâmica do mercado na educação, tendo em vista a concorrência interna, a individualização, a diferenciação e a premiação por resultados; a subordinação formal e concreta do campo da educação aos interesses 
econômicos em contraposição à perspectiva da educação como direito social e humano (DOURADO; OLIVEIRA, 2018, p.42).

A BNCC surge como uma opção barata e de negócios para os setores privatistas que poderão alavancar suas riquezas por meio da produção de materiais didáticos, de programas de formação docente, por exemplo. Assim irá trazer, no lugar de muitos benefícios, como prometido pelas intenções divulgadas, consequências ainda mais danosas para a formação continuada de professores. Apreendemos, com as discussões feitas, que com as orientações mais recentes e, especialmente, as da BNCC, os professores têm deixado de ser protagonistas de sua formação e atuação.

Para todos os efeitos houve consenso na implantação da BNCC, mas se faz notório que algumas associações, os sindicatos, inúmeros educadores, dentre outros sujeitos, foram contrários à sua instituição. Portanto, não foi resultado de um consenso. Ademais, ela surge em meio a discursos doutrinários que modelam sistemas e instituições educacionais baseadas nas expectativas dos organismos internacionais. Diante das considerações aqui tecidas neste texto, depreendemos que mesmo que os interesses do mercado tenham prevalecido, cabe a toda sociedade manter-se alerta e procurar lutar para que seus direitos já consolidados não sejam retirados.

\section{CONSIDERAÇÕES FINAIS}

Após a discussão aqui empreendida, consideramos que nesse contexto o Estado, ao mesmo tempo em que limita seu ônus com as políticas educacionais, aumenta as estratégias de controle, utilizando artifícios de mensuração e implementação de indicadores de desempenho e avaliação de resultados educacionais, que levam os docentes a uma corrida desenfreada por resultados, fazendo com que estes se sintam responsáveis por metas estabelecidas a priori, isentando, assim, o Estado de sua responsabilidade com a qualidade da educação. Todo este contexto é afiançado pela mídia que fortalece, perante a sociedade, a culpabilidade do professor nessa ambiência em que as formações são executadas, trazendo frustração e muito pouco de prática, e embasamento teórico, para que possam nortear sua atuação em sala de aula.

Mesmo mediante um quadro sombrio relacionado às políticas sociais e educacionais, num momento de retrocessos e perdas de direitos que nos vêm sendo apresentados na atual política conservadora e de extrema direita em nosso país, não podemos perder a esperança e nem a coragem para lutar em prol de uma educação de maior qualidade.

Nesse sentido, finalmente reafirmamos a importância que deve ser dada às políticas públicas, demarcadas no investimento financeiro, na superação das descontinuidades dos projetos e na efetiva consolidação boas práticas de formação em nosso país. Ressaltamos a urgência da luta coletiva em busca da consolidação de políticas de estado comprometidas com as mudanças na empreitada da formação de professores e de sua valorização, que vai, certamente, incidir na melhoria da qualidade de ensino nas escolas públicas em nosso país.

\section{REFERÊNCIAS}


ALVARADO PRADA, Luís Eduardo. Formação participativa de docentes em serviço. Taubaté: Cabral Editora Universitária, 1997.

ANADON, Simone Barreto; GONÇALVES, Suzane da Rocha Vieira. Uma ponte para o Futuro: (des)continuidades nas políticas de formação de professores. Momento: diálogos em educação, E-ISSN 2316-3100, v. 27, n. 2, p. 35-57, mai./ago, 2018. Disponível em: <https://periodicos.furg.br/momento/article/view/8181>. Acesso em: 28 set. 2019.

BAZZO, Vera; SCHEIBE, Leda. De volta para o futuro... retrocessos na atual política de formação docente. Revista Retratos da Escola, Brasília, v. 13, n. 27, p. 669-684, set./dez. 2019. Disponível em:

<http://retratosdaescola.emnuvens.com.br/rde/article/view/1038>. Acesso em: 30 jan. 2020.

BORGES, Maria Celia; AQUINO, Orlando Fernández; PUENTES, Roberto Valdés. Formação de professores no Brasil: história, políticas e perspectivas. Revista HISTEDBR online, Campinas, n. 42, p. 92-112, jun. 2011.

BRASIL. RESOLUÇÃO CNE/CP Nº 2, DE 01 DE JULHO DE 2015. Define as Diretrizes Curriculares Nacionais para a formação inicial em nível superior (cursos de licenciatura, cursos de formação pedagógica para graduados e cursos de segunda licenciatura) e para a formação continuada. Disponível em: $<$ http://portal.mec.gov.br/index.php?option=com_docman\&view=download\&alias $=136$ 731-rcp002-15-1\&category_slug=dezembro-2019-pdf\&Itemid=30192>. Acesso em 20 de fev. 2020.

BRASIL. Resolução CNE $N^{o}$ 2, De 20 de dezembro de 2019. Resolução CNE no 2, de 20 de dezembro de 2019, que define as Diretrizes Curriculares Nacionais para a Formação Inicial de Professores para a Educação Básica e institui a Base Nacional Comum para a Formação Inicial de Professores da Educação Básica (BNC-Formação). Disponível em: <http://portal.mec.gov.br/docman/dezembro-2019-pdf/135951-rcp00219/file>. Acesso em 02 de fev. 2020.

CANDAU, Vera Maria Formação continuada de professores/as: tendências atuais. In: CANDAU, Vera Maria (org.). Magistério: construção e cotidiano. Petrópolis, RJ: Vozes, 1997.

CÁSSIO, Fernando L. Base Nacional Comum Curricular: ponto de saturação e retrocesso na educação. Revista Retratos da Escola, Brasília, v. 12, 2018. Disponível em: http://retratosdaescola.emnuvens.com.br/rde/article/view/887/pdf. Acesso em: 05 jan. 2020.

CHIMENTÃO, Liliam Kemmer. O significado da formação continuada docente. In: CONGRESSO NORTE PARANAENSE DE EDUCAÇÃ̃O FÍSICA ESCOLAR, 4., 2009, Londrina. Trabalhos apresentados [...]. Londrina: UEL, 2009. Disponível em: http://www.uel.br/eventos/conpef/conpef4/trabalhos/comunicacaooralartigo/artigocomo ral2.pdf. Acesso em: 03 jun. 2017.

DOURADO, Luiz Fernandes. Formação de profissionais do magistério da educação básica: novas diretrizes e perspectivas. Comunicação \& Educação. Ano XXI. número 1. jan/jun 2016. Disponível em: 
http://www.revistas.usp.br/comueduc/article/view/110712/112709. Acesso em: $11 \mathrm{fev}$. 2019.

DOURADO, Luiz Fernandes; OLIVEIRA, João Ferreira de. Base Nacional Comum Curricular (BNCC) e os impactos nas políticas de regulação e avaliação da educação superior. In: A BNCC na contramão do PNE 2014-2024: avaliação e perspectivas. Organização: Márcia Angela da S. Aguiar e Luiz Fernandes Dourado [Livro Eletrônico]. - Recife: ANPAE, 2018: Disponível em: <http://www.anpae.org.br/BibliotecaVirtual/4-Publicacoes/BNCC-VERSAOFINAL.pdf $>$. Acesso em: 10 jan. 2020

FERREIRA, Jorge Carlos Felz. Reflexões sobre o ser professor: a construção de um professor intelectual. Biblioteca Online de Ciências da Comunicação, 2003. p. 1-8. Disponível em: <http:www.bocc.ubi.pt/pag/feliz_jorge_reflexões-sobre-serprofessor.pdf.> Acesso em: 09 maio18.

FREITAS, Luiz Carlos de. Escolas aprisionadas em uma democracia aprisionada: anotações para uma resistência propositiva. Rev. HISTEDBR On-line, Campinas, v.18, n.4 [78], p.906-926, out./dez. 2018. Doi: 10.20396/rho.v18i4.8654333. Disponível em: <https://periodicos.sbu.unicamp.br/ojs/index.php/histedbr/article/download/8654333/19 019/>. Disponível em: 25 set. 2019.

GADOTTI, Moacir. Pedagogia da práxis. São Paulo: Cortez; Instituto Paulo Freire, 1998. p. 1-5. Disponível em: <http://docplayer.com.br/52813522-Pedagogia-da-praxismoacir-gadotti.html>. Acesso em: abr. 2018.

GATTI, Bernadete A. Análise das políticas públicas p ara formação continuada no Brasil, na última década. Revista Brasileira de Educação, v. 13, n. 37, jan./abr. 2008.

.; BARRETO, Elba. Professores do Brasil: impasses e desafios. Brasília: UNESCO, 2009.

A. Formação inicial de professores para a educação básica: pesquisas e políticas educacionais. Est. Aval. Educ., São Paulo, v. 25, n. 57, p. 24-54, jan./abr. 2014; Revista USP, São Paulo, n. 100, p. 33-46, dez./jan./fev. 2013-2014

GONÇALVES, Taynara Martins Resende; BORGES, Maria Célia; $O$ curso de pedagogia em foco: contribuições para a formação de professores. São Carlos: Pedro \& João Editores, 2017.

IMBERNÓN, Francisco. Formação continuada de professores. Tradução de Juliana dos Santos Padilha. Porto Alegre: Artmed, 2010.

MAGALHÃES, Solange Martins Oliveira. Formação continuada de professores: uma análise epistemológica das concepções postas no Plano Nacional da Educação (PNE 2014-2024) e na Base Nacional Comum Curricular (BNCC 2015). Revista Linhas. Florianópolis, v. 20, n. 43, p. 184-204, maio/ago. 2019. Disponível em: <http://www.revistas.udesc.br/index.php/linhas/article/view/1984723820432019184>. Acesso em: 19 jan. 2020.

NÓVOA, António. Para o estudo sócio-histórico da gênese e desenvolvimento da profissão docente. Teoria \& Educação, Porto Alegre: Pannonica Editora Ltda., n. 4, p. 109-139, 1991.

Profissão professor. Lisboa: Porto Editora. 1995 
PAULA, Simone Grace. Formação continuada de professores: perspectivas atuais. Pandéia . do curso de pedagogia da Faculdade de Ciências. Humanas e Sociais. Univ. FUMEC, Belo Horizonte, ano 6, p. 65-86, jan./jun. 2009.

REZENDE, Valéria Moreira; ISOBE, Rogéria Moreira. Resende. Formação docente e a necessidade da formação política sob o olhar dos professores universitários. In:

BORGES, Maria Célia; RICHTES, Leonice Matilde; VIEIRA, Vânia Maria de Oliveira (org.). A formação de professores/as um olhar multidimensional. São Carlos: Pedro \& João Editores, 2017.

SANTOS, Edlamar Oliveira dos. Políticas de formação continuada para professores da Educação Básica. [S.l.]: Instituto Federal de Pernambuco. 2011. Disponível em: $<$ http://www.anpae.org.br/simposio2011/cdrom2011/PDFs/trabalhosCompletos/comuni cacoesRelatos/0141.pdf>. Acesso em: 10 nov. 2017.

SECO, Ana Paula, AMARAL; Tânia Conceição Iglesias. Período Pombalino. Revista HISTEDBR. Disponível em: <http://www.histedbr.fe.unicamp.br/navegando/periodo_ pombalino_intro.html>. Acesso em: 05 jun. 2018.

VEIGA, Ilma Passos Alencastro. A aventura de formar professores. Campinas: Papirus, 2009.

VOLSI, Maria Eunice França. Políticas para formação de professores da Educação Básica em Nível Superior: em discussão as novas Diretrizes Nacionais para a Formação dos Profissionais do Magistério. Anais do XXIV Seminário Nacional Universitas/BR. Universidade Estadual de Maringá - 18 a 20 de maio de 2016. Disponível em: <http://www.ppe.uem.br/xxivuniversitas/anais/trabalhos/e_6/6-015.pdf>. Acesso em: 29 jan. 2018.

Recebido em: 14/02/2019

Aprovado em: 11/04/2019 